\title{
Age-dependent losses in the penetrability of mouse eggs
}

\author{
D. P. Wolf and Mitsuma Hamada \\ Division of Reproductive Biology, Department of Obstetrics and Gynecology, and \\ Department of Biochemistry and Biophysics, University of Pennsylvania School of Medicine, \\ Philadelphia, Pennsylvania 19174, U.S.A.
}

The fertilizable life of mammalian eggs retained in the oviduct is limited; in the mouse, estimates vary from 10-15 hr (for review, see Iwamatsu \& Chang, 1971), but the effect of egg age on the kinetics of sperm penetration has not been examined thoroughly. In considering age-dependent losses in egg fertilizability, both in vivo and in vitro, we were interested in differentiating between changes occurring at the zonal level versus those affecting the sperm-egg fusion process, i.e. vitellus-related. Accordingly, sperm penetration of zona-intact and zona-free eggs was investigated.

Swiss mice (6-10 weeks of age) were induced to superovulate by i.p. injections of PMSG (7.5 i.u.; Organon) and $48 \mathrm{hr}$ later HCG (7.5 i.u.; Sigma). The unfertilized eggs were recovered and handled as described previously (Inoue \& Wolf, 1975; Wolf \& Inoue, 1976). Animals were killed approximately $14 \mathrm{hr}$ after HCG for the recovery of oocytes to be aged in vitro. Oocytes aged in vivo ( 3 and $10 \mathrm{hr}$ old) were recovered from animals killed 17 and $24 \mathrm{hr}$ after the HCG injection, since ovulation was considered to be completed by $14 \mathrm{hr}$ after HCG (Edwards \& Bates, 1959). Eggs recovered at these times are known to be highly and poorly fertilizable, respectively (Iwamatsu \& Chang, 1971). Cumulus cells around the 3 -hr-old eggs were removed in culture medium containing $0.1 \%$ hyaluronidase (Sigma), and zonae pellucidae were removed mechanically by aspiration through micropipettes (Wolf, Inoue \& Stark, 1976). Zona-intact and zona-free eggs were aged for up to $5 \mathrm{hr}$ in vitro and then inseminated in the same dishes with approximately $1 \times 10^{5}$ capacitated epididymal spermatozoa $/ \mathrm{ml}$, as described previously (Wolf \& Inoue, 1976). Oocytes aged in vivo were inseminated directly or after zona removal. After incubation for $3 \mathrm{hr}$, the eggs were washed, mounted, fixed, stained and examined by phase-contrast microscopy (Toyoda \& Chang, 1974). Eggs were scored as penetrated if spermatozoa were present within the zona, i.e. in the perivitelline space or in the vitellus, and fertilized if they contained enlarged sperm head(s) or pronuclei and sperm tail(s) within the vitellus. Of 80 inseminations (10-80 eggs each) involving ova aged in vitro, fertilization levels were low $(0-20 \%)$ in 16 which were excluded from analysis. Similarly, 2 of 6 inseminations of oocytes aged in vivo were excluded. The statistical significance of the results given in Table 1 was evaluated by the $\chi^{2}$ test.

Table 1. The effect of age on the numbers ( $\%$ in parentheses) of mouse oocytes penetrated, fertilized and polyspermic

\begin{tabular}{|c|c|c|c|c|c|}
\hline \multirow[b]{2}{*}{ Age (hr) } & \multicolumn{3}{|c|}{ Intact } & \multicolumn{2}{|c|}{ Zona-free } \\
\hline & Penetrated & Fertilized & Polyspermic & Fertilized & Polyspermic \\
\hline \multicolumn{6}{|c|}{ Oocytes aged in vitro } \\
\hline 0 & $64 / 76 \quad(84)$ & $57 / 76 \quad(75)$ & $14 / 76 \quad(25)$ & $93 / 93 \quad(100)$ & $68 / 93 \quad(73)$ \\
\hline 1 & $84 / 109(77)$ & $75 / 109 \quad(69)$ & $18 / 75 \quad(24)$ & $158 / 162 \quad(98)$ & $96 / 158 \quad(61)$ \\
\hline 2 & $84 / 106(79)$ & $67 / 106(63)$ & $12 / 67$ (18) & $285 / 309^{*}(92)$ & $125 / 285^{*}(44)$ \\
\hline 3 & $87 / 118(74)$ & $72 / 118 *(61)$ & $13 / 72$ (18) & $240 / 277^{*}(87)$ & $61 / 240^{*}(25)$ \\
\hline 4 & $146 / 200(73)$ & $112 / 200^{*}(56)$ & $17 / 112$ (15) & $171 / 210^{*}(81)$ & $41 / 171 *(24)$ \\
\hline 5 & $69 / 93 \quad(74)$ & $56 / 93^{*}(60)$ & $4 / 56 \quad(7)$ & $39 / 60^{*} \quad(65)$ & $9 / 39 *(23)$ \\
\hline \multicolumn{6}{|c|}{ Oocytes aged in vivo } \\
\hline 3 & $111 / 134(83)$ & $101 / 134(75)$ & $21 / 101(21)$ & $47 / 47 \quad(100)$ & $27 / 47 \quad(57)$ \\
\hline 10 & $24 / 69 *(35)$ & $13 / 69 *$ (19) & $2 / 13 \quad(15)$ & $44 / 75^{*} \quad(59)$ & $4 / 44^{*}(20)$ \\
\hline
\end{tabular}

* Significant $(P<0.05)$ decrease compared to fresh eggs. 
The percentages of penetrated, fertilized and polyspermic eggs were lower for aged eggs in all four treatment groups (Table 1). A smaller decrease in $\%$ fertilization was observed with intact eggs $(3 \% / \mathrm{hr})$ than with zona-free eggs $(7 \% / \mathrm{hr})$ aged in vitro and was presumably related to a protective effect of the zona pellucida. The rate of fertility loss seen in vitro was similar to that observed in vivo $(8 \% / \mathrm{hr})$, suggesting that the culture conditions employed were simulating the oviductal environment.

Environmental conditions may not, therefore, play a major role in the fertilization-associated responses of the mouse zona pellucida that are observed in vivo (Inoue \& Wolf, 1975; Wolf \& Inoue, 1976). The present results agree with other estimates of the fertilizable life of mouse eggs retained in the oviduct (Iwamatsu \& Chang, 1971). Eggs recovered $3 \mathrm{hr}$ after the completion of ovulation were fertilized at levels comparable to those of freshly ovulated eggs, while markedly fewer of those recovered $7 \mathrm{hr}$ later were fertilized. Previous estimates of the fertilizable life of eggs aged in vitro are unavailable. All freshly ovulated, zona-free eggs inseminated were penetrated, suggesting that they were derived from a single oocyte population, despite hormonal induction of ovulation. However, approximately $10 \%$ of the freshly ovulated, intact oocytes were not penetrated, raising the possibility of a population of eggs with defective or abnormal zonae pellucidae. These results further indicate that in-vitro penetration levels for fresh intact eggs of less than $80 \%$ are subnormal and, when appropriate, attention should be focused on the quality of the spermatozoa employed and/or the culture conditions.

The age-dependent losses in egg fertility observed here, either in vivo or in vitro, were associated with reductions in zonal and vitelline penetrability. Sperm passage through the zona, however, represents the initial step in sperm entrance and must, therefore, be considered the primary causative agent in any fertility loss attributable to decreased penetrability. Marston \& Chang (1964) concluded that fertility loss was due principally to alterations in the vitelline surface, since they occasionally observed supplemental spermatozoa in aged ova. In the present study, the percentage of inseminated ova that contained only supplemental spermatozoa ( $\%$ penetrated $-\%$ fertilized) increased from $7-8 \%$ in the recently ovulated egg to $15-16 \%$ following ageing. Obviously, in this population, fertility loss was related to vitelline penetrability.

As an acellular layer composed principally of glycoproteins (Gould, Zaneveld, Srivastava \& Williams, 1971; Inoue, 1973), the zona pellucida is permeable to relatively large molecules, such as ferritin and horse-radish peroxidase (Hastings, Enders \& Schlafke, 1972). Undoubtedly, a thick, porous structure of this nature is sensitive to environmental conditions, such as $\mathrm{pH}$ and ionic strength. Age-dependent losses in zona penetrability may, therefore, simply reflect physical alteration (shrinkage) of the zona following ovulation. Morphologically distinct alterations in aged oocytes have not been associated with losses in egg fertility (Marston \& Chang, 1964).

Supported by USPHS HD-07635 and Ford Foundation 65-58B grants.

\section{References}

Edwards, R.G. \& Bates, A.H. (1959) Timing of the stages of the maturation divisions, ovulation, fertilization and the first cleavage of eggs of adult mice treated with gonadotrophin. J. Endocr. 18, 292-304.

Gould, K., Zaneveld, L.J.D., Srivastava, P.N. \& WILliams, W.L. (1971) Biochemical changes in the zona pellucida of rabbit ova induced by fertilization and sperm enzymes. Proc. Soc. exp. Biol. Med. 136, 6-10.

Hastings, R.A. II, Enders, A.C. \& Schlafke, S. (1972) Permeability of the zona pellucida to protein tracers. Biol. Reprod. 7, 288-296.

INoue, M. (1973) Physicochemical characterization of the murine zona pellucida. Biol. Reprod. 9, 80.

INOUE, M. \& WoLF, D.P. (1975) Fertilization-associated changes in the murine zona pellucida: a time sequence study. Biol. Reprod. 13, 546-551.
IWamatsu, R. \& Chang, M.C. (1971) Factors involved in the fertilization of mouse eggs in vitro. $J$. Reprod. Fert. 26, 197-208.

Marston, J.H. \& Chang, M.C. (1964) The fertilizable life of ova and their morphology following delayed insemination in mature and immature mice. $J$. exp. Zool. 155, 237-252.

Toyoda, Y. \& Chang, M.C. (1974) Fertilization of rat eggs in vitro by epididymal spermatozoa and the development of eggs following transfer. $J$. Reprod. Fert. 36, 9-22.

Wolf, D.P. \& INOUE, M. (1976) Sperm concentration dependency in the fertilization and zonae sperm binding properties of mouse eggs inseminated in vitro. J. exp. Zool. 196, 27-38.

Wolf, D.P., Inoue, M. \& STARK, R.A. (1976) Penetration of zona-free mouse ova. Biol. Reprod. (in press). 